\title{
Preparation of Titanium Oxide-Based Nanoparticles Modified with D- (+)-Mannose and Investigation of their Properties As A Potential Drug Carrier
}

\author{
Jolanta Pulit-Prociak ${ }^{1} \cdot$ Anita Staroń $^{1} \cdot$ Olga Długosz $^{1} \cdot$ Klaudia Kluz $^{1} \cdot$ Marcin Banach $^{1}$
}

Received: 20 April 2020 / Accepted: 8 September 2020/Published online: 19 September 2020

(C) The Author(s) 2020

\section{Abstract}

Titanium oxide nanoparticles modified with D-(+)-mannose were obtained. In the process of their formation, they were conjugated with an active substance (tadalafil). The physicochemical properties of the obtained products were assessed, and the size and electrokinetic potential were determined using a dynamic light scattering technique. X-ray diffractometry was applied in order to define the crystalline properties, and Fourier-transform infrared spectroscopy was used to confirm the formation of the desired products. It was possible to obtain $\mathrm{TiO}_{2}$ coated with $\mathrm{D}-(+)$-mannose. The average size of nanoparticles was between 230 and $268 \mathrm{~nm}$. The release of the active substance from the product over a time period of three hours was assessed against the reference material, which was not modified by D- $(+)$-mannose. The results indicate that covering titanium oxide nanoparticles with the modifying substance favours a slower rate of release for the active substance, which is the desired effect from a pharmacological point of view. The releasing of active substance from modified products was even $68 \%$ slower than that from the reference product. These modified titanium oxides are promising materials that may have found an application as drug carriers.

Jolanta Pulit-Prociak

jolanta.pulit-prociak@pk.edu.pl

Anita Staroń

anita.staron@pk.edu.pl

Olga Długosz

olga.dlugosz@pk.edu

Klaudia Kluz

klaudiakluz41@gmail.com
Marcin Banach

marcin.banach@pk.edu.pl

1 Faculty of Chemical Engineering and Technology, Institute of Chemistry and Inorganic Technology, Cracow University of Technology, Warszawska 24, 31-155 Cracow, Poland 


\section{Graphic Abstract}

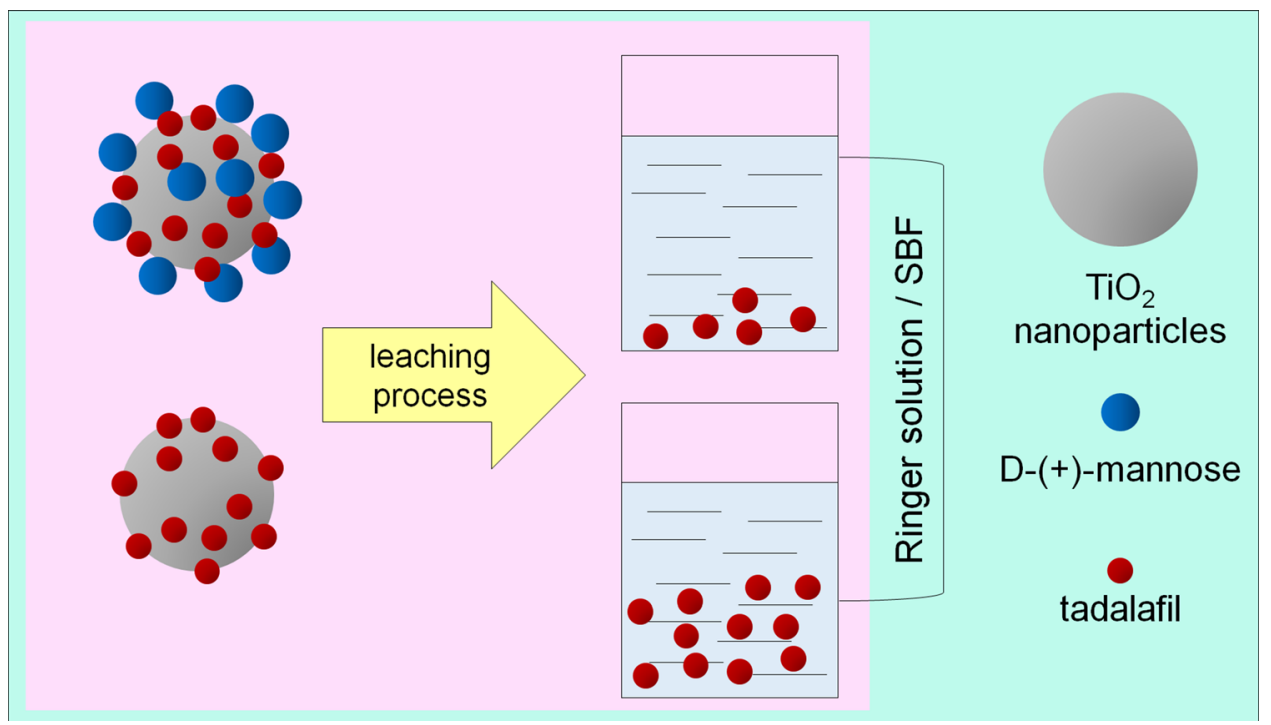

Keywords Medicine delivery systems $\cdot$ Aldohexosis $\cdot$ Tadalafil $\cdot$ Active substance releasing

\section{Highlights}

- D-(+)-mannose modification of $\mathrm{TiO}_{2}$ nanostructures leads to produce an effective drug carrier

- Coating with D-(+)-mannose does not interference the stability of $\mathrm{TiO}_{2}$ nanoparticles

- Modification with D-(+)-mannose results in slower releasing of the active substance

\section{Introduction}

Over the years, the use of nanomaterials has become increasingly widespread in numerous technological applications [1-3]. Recently, the nanomaterials have been used in medicine, in the diagnosis and treatment of diseases, including carriers of active substances in cancer treatment $[4,5]$. Alongside the active substance, the carrier is confirmed to be of crucial value for treatment [6]. Uncontrolled release of the substance, degradation of the active substance, toxic effects of the material on both cancer and healthy cells are only some of the factors that require elimination before the drug can be applied [7].

Bioconjugation of drugs and carriers is designed to increase the circulation time of the drug in the blood and to provide a stable and controlled release at the target site [8]. Polymers are the most popular materials used for this purpose, including polyethylene glycol (PEG), poly(lacticco-glycolic acid) (PLGA), and N-(2-hydroxypropyl)methacrylamide (HPMA) copolymer [9-11]. On the other hand, polymers are spherical barriers that hinder intracellular uptake. Other well-known and commonly used nanometric drug carriers include liposomes, dendrimers, polymer nanoparticles, hydrogels, carbon nanotubes, metal nanoparticles, and metal oxide nanoparticles [12, 13]. Titanium oxide is an example of a widely used drug carrier, belonging to the group of metal oxides. Nanometric $\mathrm{TiO}_{2}$ is characterized by a high hardness, hydrophilicity, good stability and chemical resistance, chemical activity, a welldeveloped surface, high surface energy, strong UV absorption, and a high oxidizing potential (Orooji, Ghasali et al. [12]; Wilczewska et al. [14]). Despite the enhanced specific surface area of $\mathrm{TiO}_{2}$ nanoparticles, active substances that bond to their surface may be released into the system in an uncontrolled manner [15]. Therefore, the modification of the surface of the nanoparticles by the attachment of additives and stabilisers makes it possible to control the release rate of the active substance [16]. These surface modification compounds simultaneously stabilize the carrier, protecting it from a changing environment. The protective coating can reduce the release of titanium ions even in the acidic environment [17]. Additives to the carriers are, among others, compounds from the hexose group, which influence the tumour-associated macrophages (TAM) [18]. The TAMs have prescriptions, which are 
characterized by a higher uptake of compounds with mannose groups. Consequently, the take up of composites modified with monosaccharide compounds combined with the drug will be higher than for normal macrophages [19].

Drug attachment may occur during carrier synthesis or after manufacturing. The carrier should be characterized by chemical inertness and high purity. The chemotherapeutic agent placed inside the carrier is protected from the surrounding environment, and at the same time, contact with healthy tissues becomes impossible [20]. The incorporation of the drug into the interior of the carrier can take place by means of nanocondensation and nanoextraction, carried out in the liquid phase. In nanoextraction, the active substance is suspended in a suitable solvent. Poor solubility of the drug causes its particles to gradually diffuse into the carriers. In nanocondensation, the drug substance should simultaneously have high affinity for the carrier and the liquid phase [21]. The solvent is adsorbed on the inner and outer surfaces of the support, and drug particles penetrate the formed layer and bind to the inner wall by van der Waals interactions.

The drug substance can be physically accumulated on the outer surface of the nanocarrier by means of adsorption ( $\pi-\pi$ interactions), adsorption, and encapsulation, or it can be coupled using bond-forming groups: amides, esters, disulphides, and $\mathrm{N}$-acetylhydrazone [22]. The ester linkage can be formed as a result of bioconjugation of the I hydroxyl group of doxorubicin (DOX) with the carboxyl group of the polymer, e.g., PLGA or I amino group of DOX with the PLGA hydroxyl group. The $\mathrm{N}$-acetylhydrazone group is obtained by joining the DOX aldehyde group with the polymer hydrazide group. Carbon nanotubes are modified, for example, using PEG with an amide group that reacts with the carboxyl moiety of the drug (paclitaxel), leading to the formation of an amide bond [23].

The carriers are captured by the cells and, then, are absorbed by endocytosis. Using a carrier protects against rapid removal of the active substance from the cell by the transmembrane drug pump [24]. Nanoparticles are surrounded by a cell membrane and transferred to the place of endosomal vesicles, which release chemotherapeutics. The rate of drug release from the carrier system can be controlled by coating the carrier surface with a suitable polymer, so the rate of diffusion of the active substance through the polymeric membrane determines this speed. When using a nanometre-sized carrier, the drug does not penetrate deep into the particle but, rather, accumulates at the surface, which is associated with a large surface-to-volume ratio and leads to a faster release of the substance [25].

The release of the drug from nanoparticles can occur in response to external stimuli or impulses flowing from inside the body. External stimuli include laser, x-ray, ultraviolet (UV), visible (Vis), near-infrared (NIR), ultrasound, magnetic field, electric field, and temperature $[26,27]$. Ultrasonic waves induce thermal and mechanical effects. Temperature-sensitive liposomes release substances under high intensity ultrasound, and extracorporeal magnetic fields are used to accumulate drug carriers at tumour sites. Good examples are nanoparticles with a coreshell structure are magnetoliposomes (maghemite nanocrystals enclosed in liposomes). The release of the drug occurs due to the heat generated by the carrier under the influence of an oscillating magnetic field [28]. Heat sensitive media, including micelles, polymers, and hydrogels, change their conformation, solubility, or hydrophilicity at a given temperature, leading to the release of the drug. The internal factor releasing the active substance can be temperature, an enzyme present in the environment of the tumour tissues (the drug can be released from liposomes under the action of the protease enzyme), $\mathrm{pH}$, or redox activity [29]. Glutathione (GSH) may reduce the disulphide bonds of carriers, leading to the release of the active substance. There is a difference in the extracellular $\mathrm{pH}$ of the tumour (6.5-6.9) and healthy tissue (7.4), and this discrepancy is due to accelerated tumour metabolism, which consumes more oxygen [30].

Referring to the above-mentioned data, the subject of this work was to obtain a modified form of titanium(IV) oxide nanoparticles by depositing mannose on their surface. This treatment aims to increase the affinity of titanium oxide as a drug carrier for cancer cells and to slow the release of the active substance from the resulting complex. The modification aimed, also, at limiting the toxicity of titanium oxide itself, which is manifested in the release of titanium ions.

Nano-titanium oxide is a universal carrier that can be used with many drugs. Tadalafil, which is a model drug, was used in this work, and there are several reasons for replacing the target active substance with it. The structure of tadalafil is based on the structure of the indole derivative. One group of anticancer drugs is an indole derivative, and in addition to doxorubicin, this group also includes nitroxine and ascorbigen [31]. Beneficial physicochemical properties of tadalafil allow its modification. Its molecular weight of $389.404 \mathrm{~g} / \mathrm{mol}$ allows for easy attachment to the metal oxide structure. Tadalafil also has a relatively high mechanical stability, and it has appropriate pharmacokinetic parameters. Its half-life is $17.5 \mathrm{~h}$ [32]. Furthermore, determination of tadalafil's concentration is possible using standard analytical techniques, such as UV-Vis spectrophotometry. It has a low toxicity, compared to commonly used anticancer drugs. From the practical point of view, no special precautions, other than standard laboratory precautions, are required when working with this substance. Lastly, the relatively low price of tadalafil means 


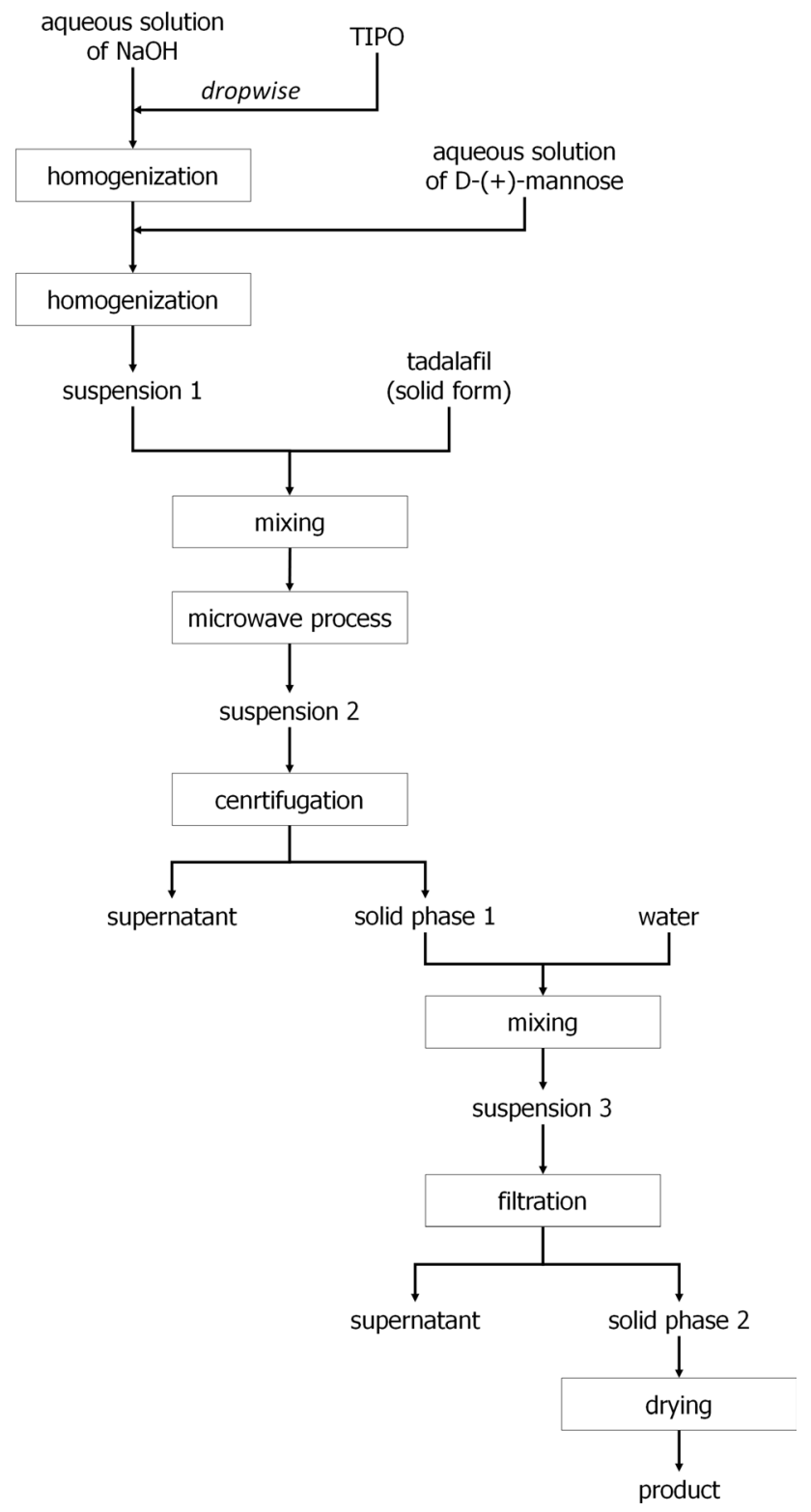

Fig. 1 Schematic diagram of the process

that its use in research is not associated with high financial outlays.

\section{Materials and Methods}

\section{Materials}

The following compounds were used in this study: titanium(IV) isopropoxide (TIPO, 97.0\%), sodium hydroxide ( $\geq$ 98.- \%), Tadalafil (Pharmaceutical Secondary Standard; Certified Reference Material), and D-(+)-mannose ( $\geq 99.0 \%$ ). For the preparation simulated body fluid sodium chloride $(\geq 99.0 \%)$, sodium bicarbonate
( $\geq 99.7 \%$ ), potassium chloride $(99.0 \%)$, dibasic potassium phosphate (ACS reagent), magnesium chloride hexahydrate ( $\geq 99.0 \%$ ), hydrochloric acid (ACS reagent, 37.0\%), calcium chloride $(\geq 93.0 \%)$, sodium sulphate anhydrous $(\geq 99.0 \%), \quad$ and tris(hydroxymethyl)aminomethane ( $\geq 99.8 \%$ ) were used. Ringer tablets (for the preparation of Ringer solution), and dimethylformamide (DMF, 99.8\%). All compounds were obtained from Sigma-Aldrich. All aqueous solutions were prepared using deionised water (Polwater, $0.18 \mu \mathrm{S}$ ).

\section{Methods}

\section{Preparation of Modified Titanium Oxide(IV) Nanoparticles} Loaded With Active Substance

The method for producing titanium oxide nanoparticles involved several steps, i.e., basic hydrolysis, polycondensation, and dehydration. Hydrolysis of titanium isopropoxide, in the presence of a base, led to the formation of titanium hydroxide. In the next stage, titanium hydroxide particles were polycondensated with the release of water. In the last stage, the condensation product was dehydrated to titanium(IV) oxide and water. The schematic diagram for the process is presented in Fig. 1.

Briefly, titanium(IV) isopropoxide was added dropwise to the aqueous solution of sodium hydroxide. The reaction mixture was homogenized directly in a Teflon vessel using an ultrasound homogenizer, Hielscher UP400St, Germany $(40 \mathrm{~W})$. After two minutes of homogenization, an aqueous solution of D-(+)-mannose was added, and the whole solution was homogenized for another $2 \mathrm{~min}$. Next, the powder of tadalafil was introduced to the reaction mixture, and the obtained suspension 1 was mixed with a magnetic stirrer for $5 \mathrm{~min}$. Then, the Teflon vessel was placed in the microwave reactor, Magnum v2, Ertec, Poland. The mixture was held at $180{ }^{\circ} \mathrm{C}$ and a pressure of 15-20 bars for $10 \mathrm{~min}$. The whole process lasted for $30 \mathrm{~min}$, and the reaction mixture stayed at the maximum temperature for five minutes. By using a pressure reactor, it is possible to achieve a temperature for the reaction mixture that exceeds $100{ }^{\circ} \mathrm{C}$, while increasing pressure. The process uses a polar solvent (water). As a result, for the process conducted in the microwave radiation field, it is possible to quickly and efficiently transfer heat to the entire volume of the reaction mixture, which significantly speeds up completion of the process. The complex of pure titanium oxide with tadalafil was the reference material. The amounts of all reagents were calculated so the mass ratio of tadalafil to the whole $\mathrm{TiO}_{2}$-Tad complex was equal to $1.0: 3.5$.

Titanium oxide nanoparticles have been modified by depositing mannose on them. Three modified materials were obtained, differing in the amount of reagents used for 
Table 1 The amounts of individual components used to prepare reaction mixtures and values of physicochemical properties of obtained products

\begin{tabular}{lcccc}
\hline Reagent & Reference product & A1 & A2 & A3 \\
\hline Water, $\mathrm{mL}$ & 31.6 & 27.2 & 20.5 & 6.5 \\
$\mathrm{C}_{\mathrm{NaOH}}, \mathrm{mol} / \mathrm{L}$ & 0.035 & 0.075 & 0.052 & 0.263 \\
$\mathrm{~V}_{\mathrm{NaOH}}, \mathrm{mL}$ & 34.0 & 32.0 & 22.9 & 13.7 \\
$\mathrm{~V}_{\mathrm{TIPO}}, \mathrm{mL}$ & 6.0 & & & \\
$\mathrm{~V}_{\text {man }}(\mathrm{C}=0.200 \mathrm{~mol} / \mathrm{L}), \mathrm{mL}$ & - & 2.0 & 11.1 & 20.3 \\
$\mathrm{~m}_{\text {tad }}, \mathrm{g}$ & 0.612 & & & \\
$\mathrm{n}_{\text {man }}: \mathrm{n}_{\mathrm{TiO} 2}$ & - & 0.02 & 0.11 & 0.20 \\
Fold of NaOH vs. stoichiometric amount & 1 & 2 & 1 & 3 \\
$\mathrm{pH}$ & 6.09 & 9.07 & 7.47 & 9.41 \\
$\mathrm{~d}, \mathrm{~nm}$ & 268 & 230 & 268 & 266 \\
lzetal, $\mathrm{mV}$ & 49.8 & 50.2 & 49.8 & 45.1 \\
\hline
\end{tabular}

their synthesis. Specific values of reagent amounts are provided in Table 1.

The physicochemical properties of the obtained materials were studied. Samples in powder form were subjected to $\mathrm{x}$-ray diffraction (XRD) analysis to confirm receipt of $\mathrm{TiO}_{2}$ (X'Pert PW 1752/00, Philips). Powder XRD patterns were recorded at $\mathrm{CuK} \alpha, \lambda=1.1540598 \AA$ ). Fourier-transform infrared spectroscopy (FT-IR) analysis was also carried out in the range of $400-3900 \mathrm{~cm}^{-1}$, which was used to determine the organic functional groups present in the products (Nicolet 380 spectrophotometer, Thermo Fisher). The surface topography of products was also examined with elemental analysis, which was carried out using both the scanning electron microscope with an x-ray scattering spectrometer (SEM-EDS) and the transmission electron microscope (TEM). The studies were performed using a 1430 VP microscope (LEO Electron Microscopy Ltd) and a Tecnai TEM (TEM G2 F20X-Twin 200 kV, FEI), respectively. To determine the $\mathrm{pH}$ value, aqueous suspensions of $1 \%(\mathrm{~m} / \mathrm{m})$ were prepared. The measurement was made with an Elmetron $\mathrm{pH}$ electrode. The size and electrokinetic potential of titanium oxide particles was also analysed using the dynamic light scattering (DLS) technique. For this purpose, aqueous suspensions of products at a concentration of $10 \mathrm{ppm}$ were made (by diluting the $1 \%$ suspension and using a Hielscher UP400St ultrasonic homogenizer). Measurements were carried out using a Zetasizer Nano ZS (Malvern Instruments Ltd.).

\section{Determination of the Active Substance Concentration}

The concentration of tadalafil was determined using a spectrophotometric technique. Since the analysis of the active substance was performed in both SBF and Ringer solution, the determination of the active substance was also completed in these leaching agents. SBF solution was freshly prepared according to a known protocol Rohanová et al. [33]. Ringer solution was prepared according to the instructions provided by the producer. Two stock solutions of tadalafil in DMF at a concentration of $200 \mu \mathrm{g} / \mathrm{mL}$ were prepared in both SBF and Ringer solution, which resulted in receiving " $\mathrm{A}$ " solutions. Then, $25 \mathrm{~mL}$ of solution " $\mathrm{A}$ " was introduced to volumetric flasks with a capacity of $50 \mathrm{~mL}$, and they were filled with the appropriate leaching agent up to the line. Thus, the " $\mathrm{B}$ " solutions of tadalafil, at $100 \mu \mathrm{g} / \mathrm{mL}$, were obtained. Both " $\mathrm{B}$ " solutions were prepared in triplicate. In order to determine the specific wavelength at which the maximum absorption of electromagnetic radiation occurs, a solution of $60 \mu \mathrm{g} / \mathrm{mL}$ was subjected to spectrophotometric analysis against water as a reference sample over the whole wavelength range (190-1100 nm, Rayleigh 1800 spectrophotometer). Three series of standard solutions, with increasing content of tadalafil, were prepared by taking appropriate amounts of solution "B" and leaching agent. The concentration of tadalafil in all standard solutions was equal to $5,10,15,20$, $25,30,35,40,45,50,55$ and $60 \mu \mathrm{g} / \mathrm{mL}$. Using these solutions, a series of calibration curves were obtained.

\section{Elution of the Active Substance from The Obtained Complexes}

First, $0.1500 \mathrm{~g}$ of tested material (reference and modified) were weighed into beakers with analytical accuracy. The appropriate amount of leaching agent was then added so that the mass-to-volume ratio of material to leaching agent was equal to $0.1 \mathrm{~g}: 2.0 \mathrm{~mL}$. The contents of the beakers were mixed on a magnetic stirrer with temperature control. The elution process was carried out during the following time points at $37{ }^{\circ} \mathrm{C}: 0.5,1,3,5,10,20,30,40,50,60$, 120, and $180 \mathrm{~min}$. After the elution time, the suspension was filtered using $0.45 \mu \mathrm{m}$ syringe filters. The obtained filtrates were tested on a UV-Vis spectrophotometer at $\lambda_{\max }$ against the reference samples, which were the leaching agents, i.e., SBF or Ringer fluid. 
Fig. 2 a XRD diffractograms indicating obtaining $\mathrm{TiO} 2$ in all cases and $\mathbf{b}$ FT-IR spectra of obtained products indicating characteristic peaks for $\mathrm{TiO} 2$ in all cases and mannose in $\mathrm{A} 1-\mathrm{A} 3$ samples
Table 2 XRD peak list with crystallites size calculated based on the Scherrer equation
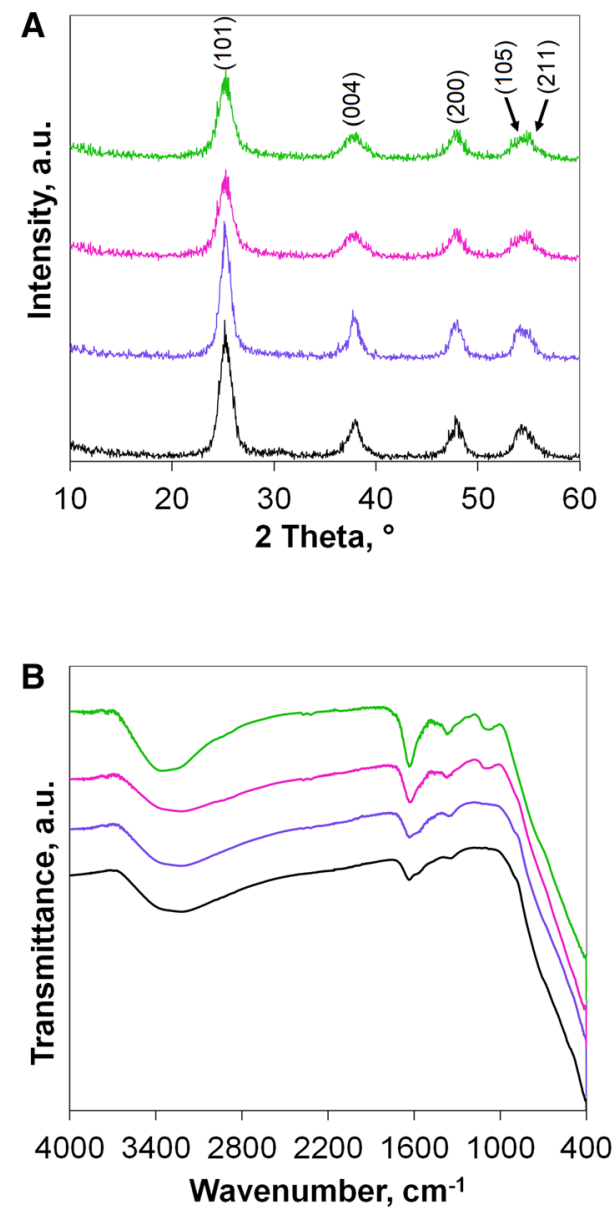

$-\mathrm{A} 1$

$-\mathrm{A} 2$

$-\mathrm{A} 3$

-Reference product
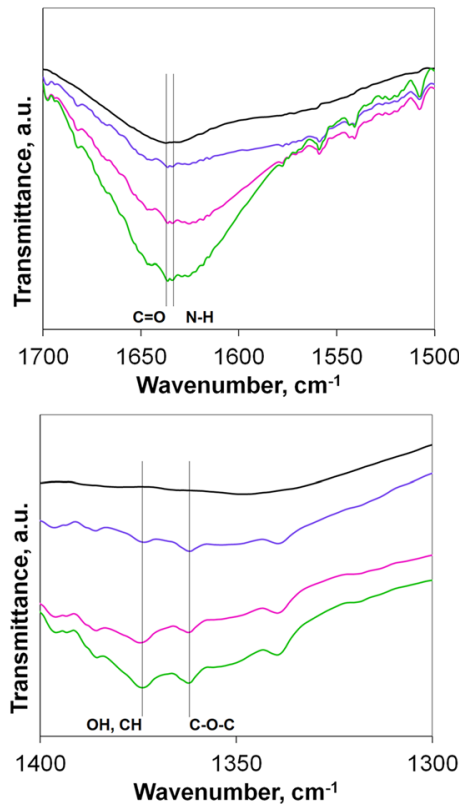

\begin{tabular}{llllll}
\hline Sample & \multicolumn{2}{l}{ Diffraction angle } & \multirow{2}{*}{ Crystallites size, nm } \\
\cline { 2 - 5 } & $2 \theta_{1},{ }^{\circ}$ & $2 \theta_{2},{ }^{\circ}$ & $2 \theta_{3},{ }^{\circ}$ & $2 \theta_{4},{ }^{\circ}$ & \\
\hline Reference product & 25.15 & 37.95 & 47.81 & 54.26 & 7.93 \\
A1 & 25.12 & 37.75 & 47.94 & 54.09 & 9.13 \\
A2 & 25.25 & 38.03 & 47.90 & 55.05 & 5.80 \\
A3 & 25.25 & 38.01 & 48.10 & 54.72 & 6.10 \\
\hline
\end{tabular}

\section{Results}

\section{Modified Titanium Oxide(IV) Nanoparticles Loaded With Active Substance}

The XRD diffractograms (Fig. 2a) show four reflections which indicate the receipt of titanium(IV) oxide in all samples. Reflections were clear, and no additional reflections were observed, proving the high purity of the obtained products. The specific values of angle $2 \theta$ at which the peaks occur are presented in Table 2 also provides the crystallites size calculated based on the Scherrer equation.
The size of nanoparticles does not correlate with the size of crystallites. The greatest crystallites form the smallest nanoparticles.

FT-IR analysis was performed to identify peaks associated with the presence of characteristic groups in the complexes. Figure $2 \mathrm{~b}$ presents the characteristic peaks. All curves have a wide absorption band at $3270 \mathrm{~cm}^{-1}$, which is related to the stretching vibrations of the $\mathrm{O}-\mathrm{H}$ groups, originating from adsorbed water. A characteristic peak for $\mathrm{TiO}_{2}$ appears around $700 \mathrm{~cm}^{-1}$, and it represents metal oxide stretching vibrations. Mannose peaks are visible in the spectra of products A1-A3. They occur at 1361 and 


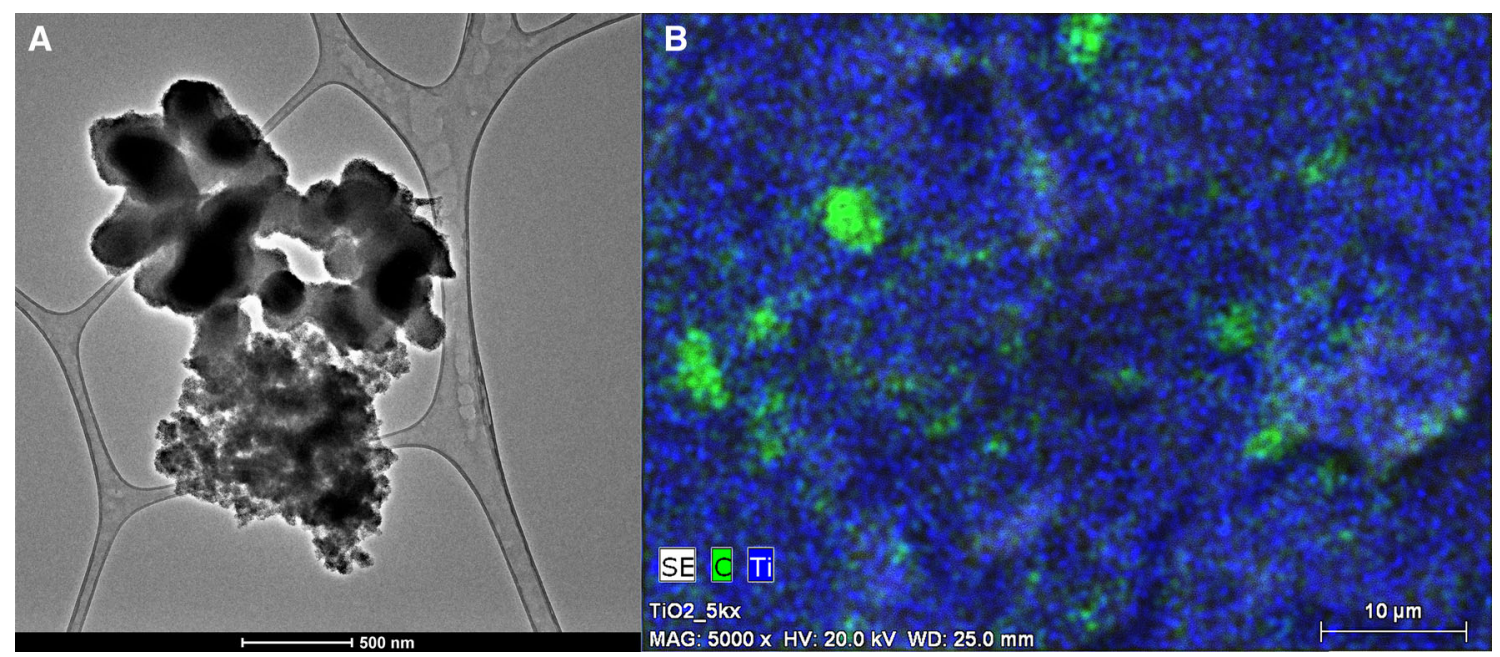

Fig. 3 a TEM microphotograph of modified carrier (A2), and (b) elementary analysis of the A2 surface presenting both inorganic and organic matter, performed with SEM-EDS
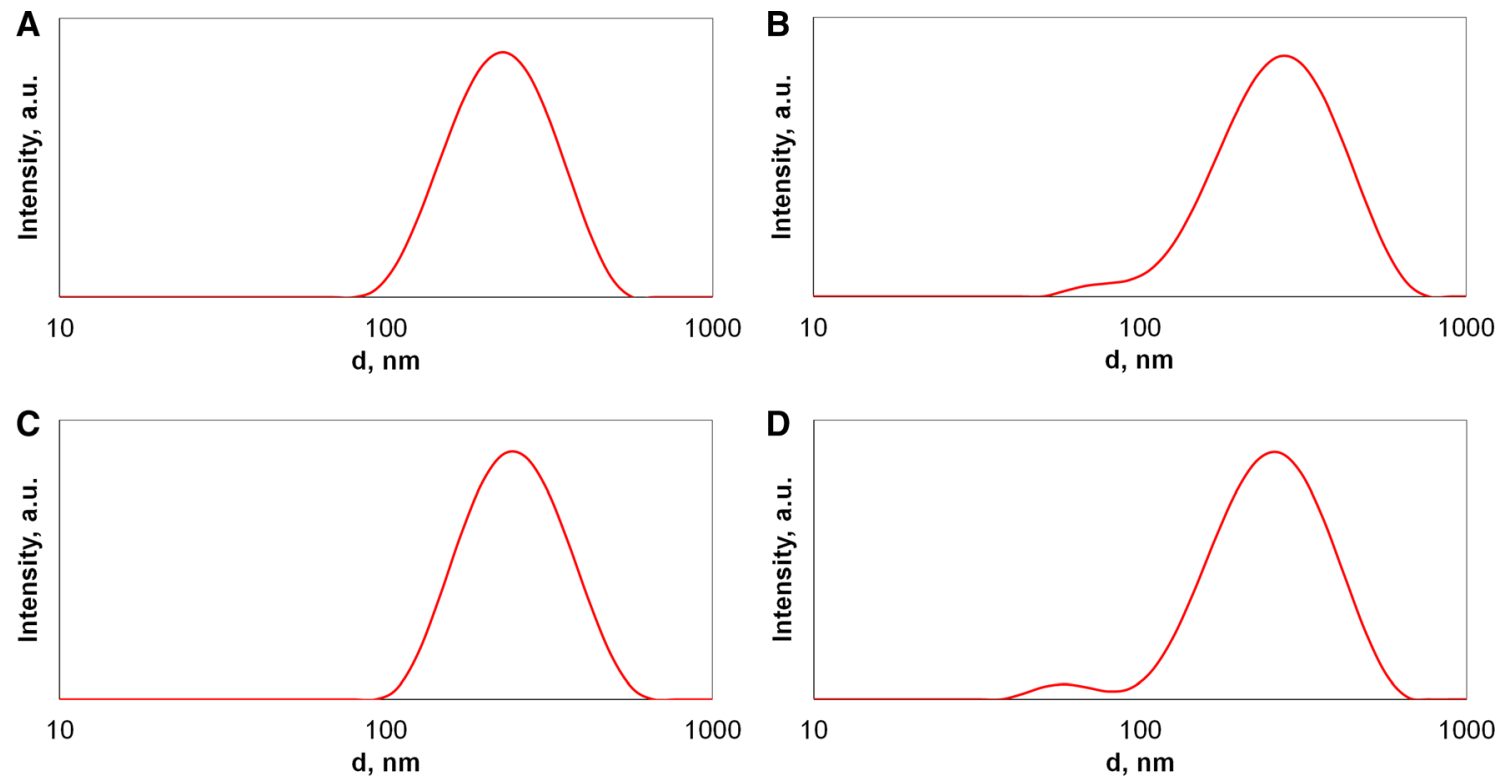

Fig. 4 DLS histograms of obtained nanoparticles (a) A1, (b) A2, (c) A3, (d) Reference product)

$1373 \mathrm{~cm}^{-1}$ and can be assigned to $\mathrm{C}-\mathrm{O}-\mathrm{C}$ vibrations and both $\mathrm{OH}$ and $\mathrm{CH}$ vibrations, respectively. The presence of tadalafil in all products is confirmed by peaks occurring at 1630 and $1637 \mathrm{~cm}^{-1}$. They represent $\mathrm{N}-\mathrm{H}$ and $\mathrm{C}=\mathrm{O}$ vibrations.

Figure $3 \mathrm{a}$ presents the results of HR-TEM analysis. Based on the microphotographs, it can be seen that nanometric-sized titanium oxide particles were obtained, which were well distributed in the tested products. In the elementary analysis (Fig. 3b), green areas indicate the presence of organic matter (mannose), which homogeneously covered the analysed material. There may be considered two groups of nanoparticles regarding their size. One group includes the particles with average size of the thinnest dimensional equal to $250-260 \mathrm{~nm}$. This observation is in line with the dominant size of particles which are provided in the course of DLS analysis. There are also visible smaller agglomerates. Their size does not exceed $100 \mathrm{~nm}$. The histogram of A2 sample obtained via DLS analysis (Fig. 4) also presents the low wide peak corresponding to particles whose size is equal to $70 \mathrm{~nm}$. These results are consistent.

Results of $\mathrm{pH}$ measurements are provided in Table 1. The lowest $\mathrm{pH}$ value is characteristic of the reference product, which is a slightly acidic material. The rest of products are alkaline, and the values of $\mathrm{pH}$ reflect the content of sodium hydroxide used in the reaction. 

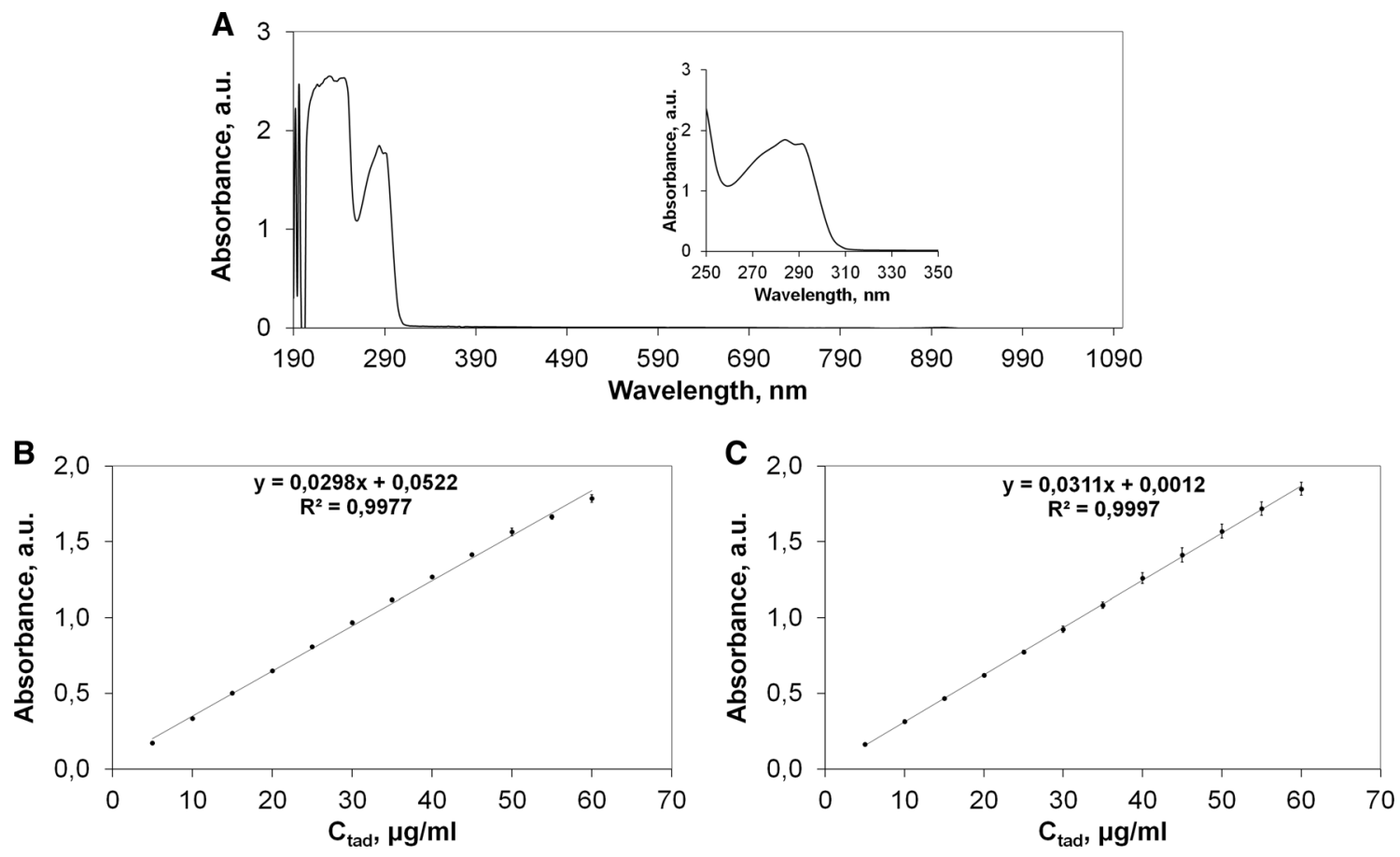

Fig. 5 a The UV-Vis spectrum of tadalafil in Ringer solution with maximum absorbance peak at $284 \mathrm{~nm}$.. Calibration curves of tadalafil in b Ringer solution and (c) SBF are shown (number of repetitions, $n=3$ )

The results of DLS analysis, shown in Table 1 and in Fig. 4, present the average size of titanium oxide nanoparticles. They were homogeneous in size, since, in all cases, one leading and dominant value was observed. The average size of $\mathrm{A} 1$ was equal to $230 \mathrm{~nm}$, while pure $\mathrm{TiO}_{2}$, $\mathrm{A} 2$, and A3, were around $267 \mathrm{~nm}$. The results show that mannose, which could be considered as a stabilising agent, had no influence on the average size of nanoparticles. In passive therapy, anatomical and physiological properties of the tumour are used. It is characterized by increased vascular permeability (leaky network of blood vessels), and the diameters of the fractures are between 100 and $800 \mathrm{~nm}$. However, in healthy tissues, they are only 2 to $6 \mathrm{~nm}$. The average size of most drugs is small and does not exceed $10 \mathrm{~nm}$. Using them on their own would cause diffusion into healthy and diseased tissues equally. Connecting them with a carrier of larger size $(230-270 \mathrm{~nm})$ would significantly reduce, or even eliminate, the penetration of medicinal substances into the structure of healthy tissues. Similarly, the developed carrier may find an application in the therapy of rheumatoid arthritis and other underlying rheumatoid diseases, which also have increased vascular permeability.

Table 1 shows the electrokinetic potential values of individual products, determined by DLS. In fact, their values were negative; however, the results prove the high stability of the aqueous suspensions, since the absolute value of the potential in each case exceeds $30 \mathrm{mV}$.

\section{Determination of Active Substance Concentration}

Figure 5a shows the spectrum of tadalafil in Ringer solution. Based on the obtained spectra, the wavelength with the highest absorption of electromagnetic radiation occurs is $284 \mathrm{~nm}$, which was consistent with previous results (Khan et al. [34]; Yunoos et al. [35]). Thus, further quantitative analysis was carried out at $284 \mathrm{~nm}$. Calibration curves in Figs. 5b, c, together with standard deviation, present the dependence of absorbance on tadalafil concentration in both Ringer solution and SBF. The values of the determination coefficients of the calibration curves $(\mathrm{R}>0.99)$ indicate that the developed analytical method for quantitative determination of tadalafil in both Ringer solution and SBF was linear.

\section{Elution of the Active Substance from the Obtained Complexes}

The concentration of tadalafil in the tested samples was calculated on the basis of the calibration curve equations, which were linear in the tested range. Graphs of tadalafil concentration in the tested filtrates against the elution time in both Ringer solution and SBF are provided in Fig. 6.

For titanium oxide nanoparticles modified with D-(+)mannose, the course of the curve that presents the leached tadalafil is expected to be lower than the reference material, 

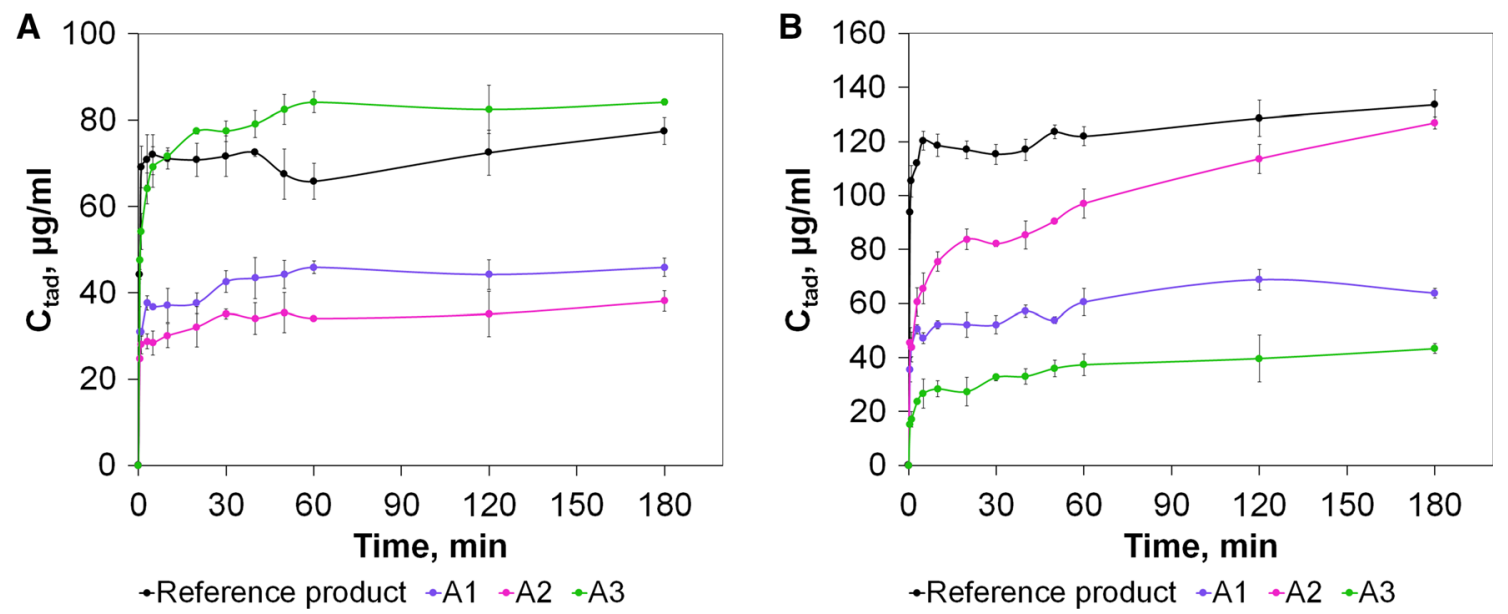

Fig. 6 The concentration of tadalafil in filtrates, depending on the elution time, are shown in (a) Ringer solution and (b) SBF (number of repetitions, $n=3$ )

but this effect was not achieved for all products. In the case of leaching performed in Ringer solution, product A3 gave the worst results because the leaching rate of tadalafil was higher than for the reference material. The leaching of tadalafil from product $\mathrm{A} 2$ was the lowest over the course of the whole experiment. For its production, the medium molar ratio of D-(+)-mannose to titanium oxide was used. Further, the level of released active agent was most stabilized in time. For reference material, an increase in the amount of tadalafil released was observed during the first five minutes. The initial peak is lower for modified products, and the amount of released substance gradually increased during the leaching. Most tadalafil was released from the A3 carrier within $180 \mathrm{~min}$, and the least amount was released from the A2 carrier.

The dependence of concentration of the released substance on the elution time in the SBF solution was the highest for the reference material and decreased in the following order: $\mathrm{A} 2, \mathrm{~A} 1$ and $\mathrm{A} 3$. In the case of pure $\mathrm{TiO}_{2}$, the mass of released substance increased, to about $120 \mu \mathrm{g} /$ $\mathrm{mL}$, during the first five minutes. Then, it remained at this level, after which it increased to about $133 \mu \mathrm{g} / \mathrm{mL}$. Most tadalafil was released from the reference and A2 materials, and the least was released from $\mathrm{A} 3$.

The A3 curve was lowest on the SBF elution plot, and the Ringer solution plot was higher than the reference material curve. In both graphs, the elution curve from product $\mathrm{A} 1$ is between the elution curves from products $\mathrm{A} 2$ and A3. The level of elution was also similar in both cases, which may indicate that the A1 carrier is the most suitable. After all, it is characterized by the highest $\mathrm{pH}$, the smallest particle size, and the highest value of electrokinetic potential, zeta.

The parameters of the product are invariable after 2 years from its fabrication; the product remains effective and safe. In order to maintain durability, it should be properly stored, i.e. in a tightly closed container, at a temperature about $20^{\circ} \mathrm{C}$. Long-lasting exposure to moisture and light radiation may cause changes in the medicinal product resulting from the photocatalytic properties of $\mathrm{TiO}_{2}$. Additionally, moisture can result the formation of agglomerates of the powder and thus reduce the quality and effectiveness of the product. The stability of this drug delivery system also depends on the expiry date of the active substance contained.

\section{Discussion}

Active transport is constantly improving the drug delivery system. Modifiers (protein, polymer, carbohydrate, etc.) are widely attached to the surface structure of the drug carriers, which is a kind of tumour receptor system, and it leads the active substance directly to its cells [36, 37]. An example of such a structure is doxorubicin combined with HPMA and galactosamine, which is used to treat liver cancer. The chemoreceptor present on hepatocytes recognizes the galactose derivative and directs the carrier to the multifunctional gland. According to the literature, this complex also arrives in healthy cells. However, in comparison with traditional treatment, the concentration of the antibiotic in infected structures is up to 50 times higher [38].

Attaching glucose or folic acid to the carrier is also a good way to deliver drugs to specific cells. Cancer needs a lot of energy to grow freely, which is why it absorbs sugar complexes more strongly. Folic acid receptors usually also appear on the surface of cancer cells. Encapsulation of nanoparticles with this substance, therefore, allows attachment of the conjugate to the changed tissue [39]. 
In addition to the requirement to release the active substance from the desired location, one of the key assumptions in drug design is the need to gradually release the active substance into the system. In special cases, the active substance is required to be released in the shortest possible time at a single, high concentration. In the case of long-term treatment, it is recommended to achieve a constant concentration of the compound with the body, effectively acting on selected cells Gioumouxouzis et al. [40]. Ejection of all the content of the compound on the carrier uses only part of its potential, making the drug ineffective. It is also important to consider critical concentration values of the active substance. Exceeding the safe dose of the compound may cause an attack on healthy cells at the same time, worsening the patient's health. On the other hand, if the minimum concentration of the substance is not achieved, the therapy becomes ineffective [41, 42] constructed dressings with controlled release of medicinal substances. Due to the gradual release of various components, the healing of wounds was faster over time compared to the temporary use of selected compounds. It was also possible to design the composition of the drug based on the place and type of wound Mostafalu et al. [42]. Venkatasubbu et al. [43] compared the release efficiency of ciprofloxacin, amoxicillin, and curcumin on a $\mathrm{TiO}_{2}$ nanocomposite with chitosan. The degree of release of medicinal substances was examined for $72 \mathrm{~h}$. It was confirmed that this value, regardless of the analysed compound, changed proportionally over time, which confirms the gradual release of active substances, obtaining the desired result Venkatasubbu et al. [43].

Liu and $\mathrm{Bi}$ [44] synthesized hollow $\mathrm{TiO}_{2}$ spheres by the hydrothermal silica etching method. Dimensions of these structures were controlled by the selection of appropriate experimental parameters. The shell thickness and the mean diameter of the hollow $\mathrm{TiO}_{2}$ spheres were 100 and $270 \mathrm{~nm}$, respectively. Doxorubicin was loaded into the carrier at high capacity and encapsulation rate. Due to the outstanding $\mathrm{pH}$ responsiveness in vitro, $\mathrm{TiO}_{2}$ structures displayed controlled drug release behaviour which released $80 \%$ of drug within $120 \mathrm{~h}$ at $5.0 \mathrm{pH}$ with a constant release rate (Liu and $\mathrm{Bi}$ [44]). Khoee et al. [45] prepared titanium dioxide nanotubes (TNTs) filled with the anticancer drug, 5-fluorouracil (5-FU) and covered with a liposomal cap to form a liposomal nanocarrier. The cumulative drug release profile from the carrier coated with $6,12,18$ and 24 liposomal layers on the surface of the nanotubes was examined. As the coating layer was thicker, the drug release rate became slower due to the stronger drug capping. The sustained drug release from TNTs was confirmed by the extended 8-21 days 5-FU release for each sample. After the burst release of drug at the first $8 \mathrm{~h}$ occurs the slow release over 1-5 weeks (Khoee et al. [45]). Tran et al. [46] developed graphene oxide immobilized titanium dioxide to efficiently carry and sustained release antimicrobial drugs for the prevention of implant-associated infection. The results show that less than $40 \%$ of the initial Dox dose loaded was released from Dox100-carrier in the first day and continued for 28 days. In the case of Dox 150-system it was below $30 \%$ for 32 days. Thus, through the vary of the initial Dox load the amount of drug released from carrier can be controlled over a range of $2-40 \mu \mathrm{g} / \mathrm{mL}$ with a sustained release for over 30 days [46].

\section{Conclusions}

Nanometric conjugates of $\mathrm{TiO}_{2}$ nanoparticles modified with D-(+)-mannose and tadalafil were successfully prepared. In the case of A1-carrier, the burst release of Tad to the SBF solution followed at the first $3 \min (51 \mu \mathrm{g} / \mathrm{mL})$, then it continued over $3 \mathrm{~h}$ to the concentration of the analyte in the liquid at the level of $64 \mu \mathrm{g} / \mathrm{mL}$. In contrast, the release of Tad from the reference product was $105 \mu \mathrm{g} /$ $\mathrm{mL}$ after $1 \mathrm{~min}$ of leaching and $134 \mu \mathrm{g} / \mathrm{mL}$ over $3 \mathrm{~h}$. These results confirm the receipt of the effective, sustained-release drug system. Titanium(IV) oxide nanoparticles, modified by depositing mannose on their surface, released the attached active substance at a constant, lowered (compared to pure $\mathrm{TiO}_{2}$ ) level within $3 \mathrm{~h}$ of introducing the product into the acceptor fluids, both Ringer solution and SBF. Reducing the amount of drug released over time reduces the drug's toxicity to the body and increases the patient's tolerance to the substance being ingested. Water suspensions of the obtained products were characterized by a very high stability, which was expressed by a high absolute value of electrokinetic potential. Thus, such products may be useful in liquid-dosage preparations.

The application of medicinal substances using such modified drug carriers would contribute to the simplification of the treatment regimen. Controlled release of the drug does not require an increase in dose or frequency of drug administration to achieve an effect identical to the result of using the immediate-release drug. It also improves the patient's tolerance profile for the drug, as well as reducing the onset and minimizing the consequences of post-pharmacological complications. Application of $\mathrm{TiO}_{2}$ nanostructures for delivery and release of the chemotherapeutic agents increases the therapeutic effect, enhancing the safety of the medicine. Carried research expands the field of application of $\mathrm{TiO}_{2}$ structures in pharmacology and contribute to the development of medical engineering. This study demonstrates that controlled release from the designed carrier with affinity for cancer cells is a promising strategy for cancer treatment, as in the therapy of underlying rheumatoid diseases. 
Acknowledgements This work is a part of the project "A method of producing non-toxic carriers of active substances based on nanomaterials," supported by the National Centre for Research and Development, Poland under the agreement LIDER/20/0080/L-9/17/NCBR/ 2018.

Open Access This article is licensed under a Creative Commons Attribution 4.0 International License, which permits use, sharing, adaptation, distribution and reproduction in any medium or format, as long as you give appropriate credit to the original author(s) and the source, provide a link to the Creative Commons licence, and indicate if changes were made. The images or other third party material in this article are included in the article's Creative Commons licence, unless indicated otherwise in a credit line to the material. If material is not included in the article's Creative Commons licence and your intended use is not permitted by statutory regulation or exceeds the permitted use, you will need to obtain permission directly from the copyright holder. To view a copy of this licence, visit http://creativecommons. org/licenses/by/4.0/

\section{References}

1. T. Vangijzegem, D. Stanicki, and S. Laurent (2019). Drug Deliv. 16, 69-78. https://doi.org/10.1080/17425247.2019.1554647.

2. Y. Orooji, M. Ghanbari, O. Amiri, and M. Salavati-Niasari (2020). J. Hazard. Mater. 389, 122079. https://doi.org/10.1016/j. jhazmat.2020.122079.

3. P. Mehdizadeh, Y. Orooji, O. Amiri, M. Salavati-Niasari, and H. Moayedi (2020). J. Clean. Prod.. https://doi.org/10.1016/j.jcle pro.2019.119765.

4. Y. Orooji, M. Haddad Irani-nezhad, R. Hassandoost, A. Khataee, S. Rahim Pouran, and S. W. Joo (2020). Spectrochim. Acta. Part. A. Mol. Biomol. Spectrosc. 234, 118272. https://doi.org/10.1016/ j.saa.2020.118272.

5. F. Ejeian, S. Azadi, A. Razmjou, Y. Orooji, A. Kottapalli, M. Ebrahimi Warkiani, and M. Asadnia (2019). Sensors. Actuators, A. Phys. 295, 483-502. https://doi.org/10.1016/j.sna.2019.06.020.

6. Z. Ye, Z. Quan, and S. Varela-Aramburu (2016). A Eur. J. 22, 15216-15221. https://doi.org/10.1002/chem.201603294.

7. M. N. Gupta and I. Roy (2020). Mol. Pharm. 17, 725-737. https:// doi.org/10.1021/acs.molpharmaceut.9b01111.

8. M. H. Kafshgari, D. Kah, A. Mazare, N. T. Nguyen, M. Distaso, W. Peukert, W. H. Goldmann, P. Schmuki, and B. Fabry (2019). Sci. Rep. 9, 1-8. https://doi.org/10.1038/s41598-019-49513-2.

9. Y. Bobde, S. Biswas, and B. Ghosh (2020). React. Funct. Polym. 151, 104561. https://doi.org/10.1016/j.reactfunctpolym.2020. 104561.

10. A. V. Prakapenka, H. A. Bimonte-Nelson, and R. W. Sirianni (2017). Ann. Biomed. Eng. 45, 1697-1709. https://doi.org/10. 1007/s10439-017-1859-8.

11. Y. Orooji, H. Khojasteh, O. Amiri, M. Amiri, S. Hasanifard, S. Khanahmadzadeh, and M. Salavati-Niasari (2020). J. Alloys. Compd. 848, 156495. https://doi.org/10.1016/j.jallcom.2020. 156495 .

12. Y. Orooji, A. Alizadeh, E. Ghasali, M. R. Derakhshandeh, M. Alizadeh, M. S. Asl, and T. Ebadzadeh (2019). Ceram. Int. 45, 20844-20854. https://doi.org/10.1016/j.ceramint.2019.07.072.

13. H. Karimi-Maleh, M. Shafieizadeh, M. A. Taher, F. Opoku, E. M. Kiarii, P. P. Govender, S. Ranjbari, M. Rezapour, and Y. Orooji (2020). J. Mol. Liq. 298, 112040. https://doi.org/10.1016/j. molliq.2019.112040.

14. A. Z. Wilczewska, K. Niemirowicz, K. H. Markiewicz, and H. Car (2012). Pharmacol. Rep. 64, 1020-1037. https://doi.org/10. 1016/s1734-1140(12)70901-5.
15. S. Çeşmeli (2019). C. Biray Avci. J. Drug Target. 27, 762-766. https://doi.org/10.1080/1061186X.2018.1527338.

16. S. Zhu, M. Niu, H. O'Mary, and Z. Cui (2013). Mol. Pharm. 10, 3525-3530. https://doi.org/10.1021/mp400216r.

17. A. I. Rezk, J. Y. Lee, B. C. Son, C. H. Park, and C. S. Kim (2019). Polymers 11, 1602. https://doi.org/10.3390/ polym 11101602 .

18. T. Ganbold and H. Baigude (2018). ACS. Appl. Mater. Interfaces. 10, 14463-14474. https://doi.org/10.1021/acsami.8b02073.

19. E. Hatami, Y. Mu, D. N. Shields, S. C. Chauhan, S. Kumar, T. J. Cory, and M. M. Yallapu (2019). Biochem. Biophys. Reports. 17, 197-207. https://doi.org/10.1016/j.bbrep.2019.01.007.

20. G. Raja, S. Cao, D. H. Kim, and T. J. Kim (2020). Mater. Sci. Eng. C. 107, 110303. https://doi.org/10.1016/j.msec.2019. 110303 .

21. E. D. Laird, H. Qi, and C. Y. Li (2015). Polymer. 70, 271-277. https://doi.org/10.1016/j.polymer.2015.06.019.

22. N. M. Meghani, H. H. Amin, and B. J. Lee (2017). Drug. Discov. Today. 22, 1604-1619. https://doi.org/10.1016/j.drudis.2017.07. 007.

23. K. Werengowska, M. Wiśniewski, A. P. Terzyk, and S. Furmaniak (2015). Adv. Condens. Matter. Phys.. https://doi.org/10. $1155 / 2015 / 198175$.

24. Y. Orooji, S. Mortazavi-Derazkola, S. M. Ghoreishi, M. Amiri, and M. Salavati-Niasari (2020). J. Hazard. Mater. 400, 123140. https://doi.org/10.1016/j.jhazmat.2020.123140.

25. R. Singh and J. W. Lillard (2009). Exp. Mol. Pathol. 86, 215-223. https://doi.org/10.1016/j.yexmp.2008.12.004.

26. M. Karimi, A. Ghasemi, P. Sahandi Zangabad, R. Rahighi, S. M. Moosavi Basri, H. Mirshekari, M. Amiri, Z. Shafaei Pishabad, A. Aslani, M. Bozorgomid, D. Ghosh, A. Beyzavi, A. Vaseghi, A. R. Aref, L. Haghani, L. Haghani, S. Bahrami, and M. R. Hamblin (2016). Chem. Soc. Rev 45, 1457-1501. https://doi.org/10.1039/ c5cs00798d.

27. X. Cui, W. Cheng, M. Dong, and X. Han (2019). New J. Chem. 43, 2752-2757. https://doi.org/10.1039/C8NJ05879B.

28. M. D. Norris, K. Seidel, and A. Kirschning (2019). Adv. Ther. 2 , 1800092. https://doi.org/10.1002/adtp.201800092.

29. X. Guo, Y. Cheng, X. Zhao, Y. Luo, J. Chen, and W. E. Yuan (2018). J. Nanobiotechnology. 16, 74. https://doi.org/10.1186/ s12951-018-0398-2.

30. X. Hu, Y. Shi, P. Zhang, M. Miao, T. Zhang, and B. Jiang (2016). Compr. Rev. Food Sci. Food Saf. 15, 773-785. https://doi.org/10. 1111/1541-4337.12211.

31. M. Su, Y. Xia, Y. Shen, W. Heng, Y. Wei, L. Zhang, Y. Gao, J. Zhang, and S. Qian (2019). RSC Adv. 10, 565-583. https://doi. org/10.1039/c9ra07149k.

32. L. Gallo, S. Pecoraro, P. Sarnacchiaro, M. Silvani, and G. Antonini (2020). Sex. Med. 8, 178-185. https://doi.org/10.1016/j. esxm.2020.02.003.

33. D. Rohanová, A. R. Boccaccini, D. M. Yunos, D. Horkavcová, I. Březovská, and A. Helebrant (2011). Acta. Biomater. 7, 2623-2630. https://doi.org/10.1016/j.actbio.2011.02.028.

34. Z. G. Khan, A. S. Patil, and A. A. Shirkhedkar (2014). Int. J. Spectrosc. https://doi.org/10.1155/2014/392421.

35. M. Yunoos, D. Gowri Sankar, B. Pragati Kumar, and S. Hameed (2010). E-Journal Chem 7, 833-836. https://doi.org/10.1155/ 2010/630576.

36. P. Boisseau and B. Loubaton (2011). Comptes Rendus Phys. 12, 620-636. https://doi.org/10.1016/j.crhy.2011.06.001.

37. F. U. Din, W. Aman, I. Ullah, O. S. Qureshi, O. Mustapha, S. Shafique, and A. Zeb (2017). Int. J. Nanomed. 12, 7291-7309. https://doi.org/10.2147/IJN.S146315.

38. L. W. Seymour, D. R. Ferry, D. Anderson, S. Hesslewood, P. J. Julyan, R. Poyner, J. Doran, A. M. Young, S. Burtles, and D. 
J. Kerr (2002). J. Clin. Oncol. 20, 1668-1676. https://doi.org/10. 1200/jco.2002.20.6.1668.

39. A. Fadaka, B. Ajiboye, O. Ojo, O. Adewale, I. Olayide, and R. Emuowhochere (2017). J. Oncol. Sci. 3, 45-51. https://doi.org/ 10.1016/j.jons.2017.06.002.

40. C. I. Gioumouxouzis, E. Tzimtzimis, O. L. Katsamenis, A. Dourou, C. Markopoulou, N. Bouropoulos, D. Tzetzis, and D. G. Fatouros (2020). Eur. J. Pharm. Sci. 143, 105176. https://doi. org/10.1016/j.ejps.2019.105176.

41. L. Guo, S. Wang, Y. He, R. Zheng, L. Chen, Y. Sun, Z. Zhang, W. Shi, and D. Ge (2018). J. Mater. Sci. 53, 9382-9392. https:// doi.org/10.1007/s10853-018-2283-7.

42. P. Mostafalu, G. Kiaee, G. Giatsidis, A. Khalilpour, M. Nabavinia, M. R. Dokmeci, S. Sonkusale, D. P. Orgill, A. Tamayol, and A. Khademhosseini (2017). Adv. Funct. Mater. 27, 1702399. https://doi.org/10.1002/adfm.201702399.
43. G. D. Venkatasubbu, S. Nagamuthu, T. Anusuya, J. Kumar, R. Chelliah, S. R. Ramakrishnan, U. Antony, I. Khan, and D H Oh Mater (2018). Res. Express.. https://doi.org/10.1088/2053-1591/ aaa936.

44. D. Liu and Y. guang Bi (2019). Adv. Powder Technol. 30, 2169-2177. https://doi.org/10.1016/j.apt.2019.06.032.

45. M. Heidari Khoee, S. Khoee, and M. Lotfi (2019). Anal. Biochem. 572, 16-24. https://doi.org/10.1016/j.ab.2019.02.027.

46. D. L. Tran, P. Thi, T. T. Hoang, and K. D. Park (2019). Colloid Surface B. 181, 576-584. https://doi.org/10.1016/j.colsurfb.2019. 06.009.

Publisher's Note Springer Nature remains neutral with regard to jurisdictional claims in published maps and institutional affiliations. 